\title{
Organizational configuration of hospitals succeeding in attracting and retaining nurses
}

\author{
Sabine Stordeur ${ }^{1}$, William D’Hoore ${ }^{2} \&$ the NEXT-Study Group ${ }^{\dagger}$
}

Accepted for publication 28 July 2006

${ }^{1}$ Sabine Stordeur MA PhD RN

Senior Researcher

${ }^{2}$ William D'Hoore MD PhD

Professor

Unité d'Epidémiologie,

de Biostatistique et de

Méthodes Opérationnelles en Santé,

Publique,

Brussels, Belgium

Correspondence to Sabine Stordeur:

e-mail: stordeur@epid.ucl.ac.be

*This study is part of the European NEXTStudy (Nurses' Early Exit Study - http:// www.next-study.net).

${ }^{\dagger}$ Germany - H.M. Hasselhorn, B.H. Müller (coordinators), P. Tackenberg, A.

Kümmerling, M. Simon, University of Wuppertal; A. Büscher, University of WittenHerdecke; Belgium - W. D’Hoore, S. Stordeur, Université catholique de Louvain; L. Braeckman, P. Kiss, R. Verpraet, Ghent University; Finland - M. Laine, G. Wickström, Turku Regional Institute of Occupational Health; France - M. EstrynBehar, O. Le Nezet, Assistance Publique Hôpitaux de Paris; Great Britain - D. Gould, St. Bartholomew School of Nursing and Midwifery, City University, London; Italy D. Camerino, P. Conway, University of Milan; Netherlands - B. Van der Heijden, E. van der Schoot, University of Twente; Poland - H. Oginska, J. Pokorski, Jagiellonian University in Krakow; P. Radkiewicz, M. Widerszal-Bazyl, Central Institute for Labour Protection, Warsaw; Slovakia - A. Hanzlikova, M. Kovarova, Department of Social Medicine, P.J. Safarik University, Kosice; Sweden - M. Josephson, P. Lindberg, Karolinska Institute.
STORDEUR S., D'HOORE W. \& THE NEXT-STUDY GROUP (2007) Organizational configuration of hospitals succeeding in attracting and retaining nurses*. Journal of Advanced Nursing 57(1), 45-58

doi: 10.1111/j.1365-2648.2006.04095.x

\section{Abstract}

Title. Organizational configuration of hospitals succeeding in attracting and retaining nurses

Aim. This paper contrasts structural and managerial characteristics of low- and high-turnover hospitals, and describes the organizational configuration of attractive hospitals.

Background. In countries facing nurse shortages and turnover, some hospitals succeed in recruiting and retaining nurses. In Magnet Hospitals, managerial practices and environmental characteristics increase nurses' job satisfaction and their commitment to the organization, which in turn decreases nurse turnover. Such an approach suggests that organizations are best understood as clusters of interconnected structures and practices, i.e. organizational configurations rather than entities whose components can be understood in isolation.

Method. From a sample of 12 hospitals whose nurse turnover was studied for 1 year, structural and organizational features of hospitals in the first and fourth quartiles, i.e. attractive (turnover $<3 \cdot 1 \%$ ) vs. conventional (turnover $>11 \cdot 8 \%$ ) were contrasted. A questionnaire, including perceptions of health-related factors, job demands, stressors, work schedules, organizational climate, and work adjustments antecedent to turnover, was received from 401 nurses working in attractive hospitals (response rate $53 \cdot 8 \%$ ) and 774 nurses in conventional hospitals (response rate $=54 \cdot 5 \%$ ).

Findings. Structural characteristics did not differentiate attractive and conventional hospitals, but employee perceptions towards the organization differed strikingly. Differences were observed for risk exposure, emotional demands, role ambiguity and conflicts, work-family conflicts, effort-reward imbalance and the meaning of work, all in favour of attractive hospitals $(P<0.001)$. Relationships with nursing management, work ability and satisfaction with working time, handover shifts and schedules were also better in attractive hospitals $(P<0 \cdot 001)$. Job satisfaction and commitment were higher in attractive hospitals, whereas burnout and intention to leave were lower $(P<0.001)$.

Conclusion. Organizational characteristics are key factors in nurse attraction and retention. Nurses face difficulties in their work situations, but some hospitals are perceived as healthy organizations. The concept of attractive institutions could serve as a catalyst for improvement in nurses' work environments in Europe. 
Keywords: Magnet Hospitals, nurse recruitment, nursing retention, organizational characteristics, questionnaire, work organisation, workforce issues

\section{Background}

In many countries, healthcare settings face difficulties in recruitment and retention of nursing staff. This problem has two origins: the nursing shortage and staff turnover. Nursing shortage is reported to be an increasing problem worldwide including in Europe (Buchan 1994, Aiken et al. 2001, Aiken 2002) resulting from increasing demand due to population growth, an ageing population, technological advances and higher patient expectations (Simoens et al. 2005). Turnover is the second possible cause of nurse staffing problems. Turnover can be either voluntary or involuntary. Research on employee turnover is concerned primarily with voluntary turnover, which is defined as 'individual movements across the membership boundary of a social system which is initiated by the individual' (Price 1977, p. 4). Voluntary turnover includes changing employer for better pay elsewhere, better working conditions, problems with a supervisor or the management, a spouse move to another location, shorter home-work distances, or prolonged pregnancy leaves. Involuntary turnover includes dismissal, layoff, forced retirement, medical disability or death (Tai et al. 1998). Most figures combine both types of turnover. For instance, in the USA, turnover rates for nursing were estimated to be between $10 \%$ and $30 \%$ in hospitals in 2000 (The HSM Group, Ltd 2002). In comparison, turnover rates were estimated to be between $15 \%$ and $20 \%$ in the UK (Zurn et al. 2005).

Socio-demographic characteristics as age, gender, work experience and tenure, marital status and kinship responsibilities predispose to turnover but are usually not considered as explanatory variables in turnover behaviour (Tai et al. 1998). Extensive literature reviews on turnover (Tai et al. 1998, Hayes et al. 2006) emphasize the role of environmental and organizational factors on turnover, highlighting the concept of a common predisposing climate for turnover. Tai et al. (1998) discuss the influence of structural characteristics such as location, ownership and facility size. For example, large metropolitan areas offer more job opportunities than rural areas; consequently, one could expect that hospitals located in urban cities record higher turnover rates (Bloom et al. 1992). If type of ownership affects organizational culture and management style, relationships between ownership and turnover rate are theoretically relevant, but are not supported by empirical findings. According to Halbur (1983), nurse turnover rates increase as organization size increases, whereas Spencer (1986) found no relationship between size and nursing turnover.

Organizational determinants of nurse turnover have been extensively studied. Direct predictors of turnover include work overload and work stress, whereas a supportive nursing management and favourable work-group climate that promotes job satisfaction and member cohesiveness have been found to be negative predictors of nursing turnover (Campion et al. 1996). A management style that values staff contribution and encourage staff involvement in decision-making also enhances organizational and professional job satisfaction, resulting in lower turnover rates (Leveck \& Jones 1996). Promotional opportunities and organizational characteristics, associated with empowerment and autonomy, have also been found to decrease the likelihood of leaving. Self-scheduling strategies may promote good balance between work and home, whereas long shifts, overtime, weekends, nights, holidays and weekend overtime have been found to be predictors of turnover (Shader et al. 2001, Strachota et al. 2003). Managerial practices and environmental characteristics influence nurses' job satisfaction and their commitment to the organization (Hayes et al. 2006). Satisfaction and commitment directly affect the choice of professionals to stay in, or to leave, the institution and are used in numerous studies as indicators of successful socialization in the workplace (Meyer \& Allen 1997, Gaertner 1999).

Most studies present turnover models that explain the relationships between exposure to job stressors (including physical and psychological risk factors), job satisfaction and turnover at an individual level (Shader et al. 2001, Strachota et al. 2003, Holtom \& O'Neill 2004, Sjögren et al. 2004). Some theoretical models also attempt to integrate the many contextual, economic, organizational and personal factors affecting turnover (Price \& Mueller 1981, Irvine \& Evans 1995). Other models focus on employee retention (Mitchell et al. 2001a, Ellenbecker 2004). Empirically, integrative models make sense and allow description of individual and institutional-level characteristics associated with turnover. It has been shown, for example, that even in countries facing severe shortages and high nurse mobility, some healthcare settings still succeeded in recruitment and retention of nurses (McClure et al. 1983, Kramer \& Schmalenberg 1988, Kramer 1990, Finlayson et al. 2002, McClure \& Hinshaw 2002), leading to the concept of Magnet Hospitals. Such an approach suggests that organizations are best understood as 
clusters of interconnected structures and practices, i.e. organizational configurations rather than entities whose components can be understood in isolation (Delery \& Doty 1996). The configurational analysis thus takes a systemic and holistic view of healthcare organizations, where patterns or profiles rather than individual independent variables are related to an outcome such as nurse turnover.

\section{The study}

\section{Aim}

The aims of this study were (1) to contrast structural and managerial characteristics of low- and high-turnover hospitals; (2) to describe unique or multiple configurations likely to lower nurse turnover; and (3) to propose a coherent model of attractive hospitals in a European context.

\section{Design}

From a theoretical viewpoint, low-turnover institutions were assumed to display an organizational profile that not only promoted nurses' job satisfaction and organizational commitment, but that also fulfilled their professional and personal needs.

To interpret variations in turnover, we explored the antecedents of commitment, job satisfaction and intent to leave, i.e. relevant managerial practices and work environment attributes (Kramer 1990, Meyer \& Herscovitch 2001). We treated hospitals as cases and used qualitative comparative analysis as a relevant analytic technique to study combinations of case characteristics linked to turnover (Ragin 1999). Contrary to conventional, variable-based approaches, qualitative comparative analysis does not disaggregate cases into independent, analytically separate aspects, but instead treats configurations as different types of cases. This method contributes to theory-building by providing rigorous support for the expression of complex causal relations in ways that generate new insights for organization understanding (Fiss 2005, see http://www. compasss.org/fiss2005.pdf).

\section{Participants}

This study stems from the European NEXT-Study (Nurses' Early Exit Study - http://www.next-study.net) which was designed to investigate the reasons, circumstances and consequences surrounding premature departure from the nursing profession (Hasselhorn et al. 2003). For the purpose of the present study, a convenience sample of 12 Belgian hospitals was recruited. The representativeness of this hospital sample was verified according to the following criteria: (1) geographical location (urban/rural areas); (2) status (private/ public institutions); (3) size (number of beds); and (4) specialization (general/psychiatric hospitals). The nursing population of these 12 hospitals consisted of 3798 registered nurses (qualification level at minimum 3 years of training in accordance with EU/WHO or comparable directives).

\section{Data collection}

Data were collected using a questionnaire survey with staff nurses (Registered Nurses) and an organizational assessment designed to obtain a description of structural characteristics of hospitals, and the number of nurses who voluntarily left their current institution during the year following the questionnaire survey, i.e. from September 2002 to August 2003. Self-administered questionnaires were accompanied by a cover letter explaining the purpose of the study and providing guarantees of confidentiality. Questionnaires were collected through the internal mailing system of hospitals and then retrieved by the researchers. Follow-up letters were sent to remind nurses to participate. A total of 2065 RNs completed the questionnaire, for a $54.4 \%$ response rate (range between hospitals $=43 \cdot 0-67 \cdot 9 \%$ ) (Table 1$)$.

\section{Instruments}

\section{Baseline questionnaire}

This questionnaire covered demographic data and work situations of nurses, as well as their prospects and intentions. Several scales were used to describe nurses' perceptions in the following domains: physical health-related factors, job

Table 1 Overview of hospitals and staff at baseline assessment

\begin{tabular}{lclll}
\hline Institutions & $\begin{array}{l}\text { Number of } \\
\text { institutions }\end{array}$ & $\begin{array}{l}\text { Number of staff } \\
\text { approached }\end{array}$ & $\begin{array}{l}\text { Number of staff } \\
\text { responding }\end{array}$ & $\begin{array}{l}\text { Response } \\
\text { rate (\%) }\end{array}$ \\
\hline $\begin{array}{l}\text { Hospital }>400 \text { beds } \\
\quad \text { Non-university }\end{array}$ & 1 & 377 & 244 & $64 \cdot 7$ \\
$\quad$ University & 1 & 1139 & 613 & $53 \cdot 8$ \\
Hospital $<400$ beds & 10 & 2282 & 1208 & $43 \cdot 0-67 \cdot 9$ \\
All & 12 & 3798 & 2065 & $54 \cdot 4$ \\
\hline
\end{tabular}


demands and stressors, work schedules, organizational climate and work adjustments antecedent to turnover (see Appendix). We took advantage of existing validated scales covering relevant aspects of the NEXT-Study model. A large number of the scales had been subjected to six pre-tests in three countries (Hasselhorn et al. 2003).

\section{Organizational assessment}

Organizational assessment was carried out by each institution at the beginning of the data collection period (September 2002). A questionnaire designed to describe structural parameters and economic trends, staff characteristics, and human resources management practices was filled in by the nursing director and human resources director. The questionnaire was divided into five parts:

- local factors;

- legal status of the institution;

- general characteristics of the institution (level of care, professional model of care, activity and financial balance);

- resources data (number of nurses, specialized nurses and assistant nurses; number of permanent contracts; age distribution; turnover, absenteeism; vacancies);

- human resources management in the nursing sector (job descriptions, continuing education policy, career management and clinical ladder).

\section{Nurse turnover}

From September 2002 to August 2003, all nurse executives at the 12 hospitals recorded the number of nurses who, among those who were present at baseline, voluntarily left the institution. A specific annual turnover rate could then be computed. As regards classical definitions of turnover (leavers in year/average staff level), this measure does not capture all staff movements and therefore represents a lower estimate.

\section{Definition of attractive and conventional hospitals according to nurse turnover}

Nurse turnover was not uniform across hospitals, with figures varying from $0.6 \%$ to $13.1 \%$ during the 1 -year recording. Hospitals were classified into four quartiles according to their turnover rate: (1) $0 \cdot 6-3 \cdot 1 \%$; (2) $3 \cdot 7-5 \cdot 0 \%$; (3) $6 \cdot 3-7 \cdot 4 \%$; and (4) $11 \cdot 8-13 \cdot 1 \%$. The three hospitals in the first turnover quartile were labelled 'attractive', whereas the three hospitals in the fourth turnover quartile were labelled 'conventional'. It is noticeable that the vacancy rate was $0 \%$ in low-turnover hospitals and ranged from $1.6 \%$ to $15.8 \%$ in high-turnover hospitals. Consequently, attractive hospitals succeeded in nurse recruitment and retention.
All the subsequent analyses focused on hospitals belonging to these two extreme groups, reducing the number of participating RNs from 2065 to 1175. Representativeness at the hospital level was confirmed by comparing data from human resources records with characteristics of respondents in terms of age, gender, working time, permanent working contracts and mean tenure in the hospital.

\section{Ethical considerations}

The study was approved both by management and staff representatives of the institutions. All nursing staff of participating hospitals were included. In each institution, a contact person was disseminated information about the NEXT-Study, including the research objectives, study design, methodological aspects, guarantees of confidentiality and feedback. Self-completed questionnaires were accompanied by a cover letter explaining the purpose of the study and providing guarantees of confidentiality.

\section{Data analysis}

Instead of a variable-based analytical approach through multivariate statistics, we chose qualitative comparative analysis to contrast the configurations of attractive and conventional hospitals, a method more appropriate to drawing a picture of cases where multiple factors are assumed to be interconnected within and specific to attractive institutions. According to qualitative comparative analysis, different conditions combine rather than compete with each other in creating an outcome.

Therefore, statistical analysis was only considered here as a method of summarizing data on nurse perceptions so as to obtain the profiles of attractive and conventional hospitals, which were the material used in qualitative comparative analysis. Data entry was done by optical recording. Independent sample $t$-tests and Mann-Whitney tests were used to compare means. Mann-Whitney tests were used for variables which were highly asymmetrically distributed. Chi-square tests were used to compare proportions. Results were considered statistically significant at the $P \leq 0.05$ level. All $P$-values are two-tailed. Data analysis was conducted using SPSS 11.5.

\section{Results}

\section{Structural and organizational characteristics of attractive and conventional hospitals}

The sample, including 1175 nurses, was distributed as follows: $401 \mathrm{RNs}$ in the three attractive hospitals (response 
rate $=53.8 \%)$ and 774 nurses in the three conventional hospitals (response rate $=54.5 \%$ ). Of the respondents, $87 \cdot 1 \%$ were female, $58.5 \%$ had children, $51 \cdot 3 \%$ worked full-time and $95.8 \%$ had an permanent working contract. Mean age was $37 \cdot 3$ years $(S D=9 \cdot 2)$, and average tenure in the hospital and in the profession were 4.4 years $(\mathrm{SD}=1 \cdot 1)$ and 14.5 years $(S D=9 \cdot 1)$ respectively.

In the first step, structural and organizational features of attractive vs. conventional hospitals were contrasted. Table 2 shows selected indicators of hospital structure, activity, financial results, human resources management and nursing. As can be seen, characteristics were similarly distributed among attractive and conventional hospitals. On the one hand, the absence of structural differences between attractive and conventional hospitals may be explained by Belgian healthcare system regulations: complementarities between the public and the private (mostly not-for-profit) sectors, comparable levels of resources, same financing mechanisms, same legislation on personnel qualifications. This may also explain why increases in admissions and decreases in mean length of stay were observed in both groups, with diverse financial results. Moreover, Belgian legislation does not define career requirements nor clinical ladders. On the other hand, reorganizations that had occurred in the past 3 years were generally minor and voluntary. Finally, nursing practice was identified in both groups as patient-centred care, which was assumed to be appropriate given the case-mix and nursing resources (13 nurses/30 acute beds).
In the second step, the socio-demographic data of RNs and profiles of nurse perceptions towards the organization were compared between attractive and conventional institutions (Table 3). These profiles differed strikingly between attractive and conventional hospitals.

\section{Employment and demographic characteristics}

Several employment and personal characteristics differed between attractive and conventional hospitals. In attractive hospitals, nurses were older (mean $=38.8$ vs. 37.2 years; $P=0.005$ ) and had a higher institutional seniority (mean = 4.68 vs. 4.42 years; $P<0.001)$ than in conventional hospitals; they also had more children (mean $=1.41$ vs. 1.09; $P<0.001$ ). They perceived lower opportunities for job alternatives in the same area (mean $=3.81$ vs. $4 \cdot 11$; $P<0.001)$. Home-workplace travelling distances were shorter for nurses working in attractive institutions (mean = 34.4 minutes vs. 43.4 minutes; $P<0.001$ ), meaning either that nurses lived in close to their workplace or in regions with less dense traffic (suburbs and rural). Unexpectedly, the proportion of employees with permanent contracts was higher in conventional hospitals (90.8 vs. $98.4 \%$; $P<0.001)$.

The higher proportion of male nurses in attractive hospitals (18.4 vs. $10 \cdot 1 \% ; P<0.001)$ was due to the presence of a psychiatric service caring for dangerous sex offenders. The higher male proportion was in turn linked to the lower proportion of part-time positions.

Table 2 Structural and organizational features of attractive and conventional hospitals

\begin{tabular}{|c|c|c|}
\hline & Attractive hospitals $(n=3)$ & Conventional hospitals $(n=3)$ \\
\hline Legal status & 2 public/1 private & 2 private/1 public \\
\hline Size (beds) & $3<400$ beds & $\begin{array}{l}2<400 \text { beds } \\
1>400 \text { beds }\end{array}$ \\
\hline Any form of reorganization & 3 yes & 2 yes $/ 1$ no \\
\hline $\begin{array}{l}\text { Increase in the number of inpatients and outpatients } \\
\text { from } 1999 \text { to } 2001\end{array}$ & 3 yes & 3 yes \\
\hline Decrease in mean length of stay from 1999 to 2001 & 3 yes & 3 yes \\
\hline Financial balance & 1 loss/1 balanced/1 profit & 1 loss/1 balanced/1 profit \\
\hline $\begin{array}{l}\text { Increase in the number of permanent contracts from } \\
1999 \text { to } 2001\end{array}$ & 3 yes & 3 yes \\
\hline Job description & 3 yes & 3 yes \\
\hline Required qualification level for the nursing sector & 3 yes & 3 yes \\
\hline Professional model of care & $\begin{array}{l}2 \text { patient-centred care } \\
1 \text { primary nursing }\end{array}$ & 3 patient-centred care \\
\hline Frequency of continuing education sessions & $\begin{array}{l}2 \text { monthly } \\
1 \text { quarterly }\end{array}$ & 3 monthly \\
\hline Career planning & 3 no & 3 no \\
\hline Clinical ladder for nurses & 3 no & 3 no \\
\hline
\end{tabular}


Table 3 Profiles of employment and nurses' perceptions of work situations in attractive and conventional hospitals

\begin{tabular}{|c|c|c|c|}
\hline & $\begin{array}{l}\text { Attractive hospitals } \\
(n=401 \text { nurses })\end{array}$ & $\begin{array}{l}\text { Conventional hospitals } \\
\text { ( } n=774 \text { nurses) }\end{array}$ & $P$ value \\
\hline \multicolumn{4}{|l|}{ Local factors } \\
\hline Job alternatives in the same area & $3 \cdot 81(0 \cdot 94)$ & $4 \cdot 11(0 \cdot 91)$ & $0 \cdot 001$ \\
\hline Distance home-hospital (minutes)* & $34 \cdot 4(26 \cdot 2)$ & $43.4(33.6)$ & $0 \cdot 001$ \\
\hline \multicolumn{4}{|l|}{ Personal characteristics of nurses } \\
\hline $\operatorname{Sex}(\% \text { men })^{*}$ & $18 \cdot 4$ & $10 \cdot 1$ & $0 \cdot 001$ \\
\hline $\operatorname{Age}^{*}$ & $38 \cdot 85(8 \cdot 65)$ & $37.24(9.09)$ & $0 \cdot 005$ \\
\hline Number of children* & $1 \cdot 41(1 \cdot 19)$ & $1 \cdot 09(1 \cdot 17)$ & $0 \cdot 001$ \\
\hline \multicolumn{4}{|l|}{ Employment } \\
\hline Seniority (years)* & $4.68(0.73)$ & $4.42(1.05)$ & $0 \cdot 001$ \\
\hline Permanent contract $(\%)^{*}$ & $90 \cdot 8$ & $98 \cdot 4$ & $0 \cdot 001$ \\
\hline Part-time $(\%)^{*}$ & $42 \cdot 9$ & $51 \cdot 7$ & $0 \cdot 004$ \\
\hline \multicolumn{4}{|l|}{ Physical health-related factors } \\
\hline Exposure to toxic substances & $1 \cdot 3(1 \cdot 28)$ & $2 \cdot 22(1 \cdot 14)$ & $0 \cdot 001$ \\
\hline Exposure to infection & $2.51(0.99)$ & $3 \cdot 24(1 \cdot 28)$ & $0 \cdot 001$ \\
\hline Exposure to noise & $1 \cdot 25(1 \cdot 14)$ & $2 \cdot 66(1 \cdot 13)$ & $0 \cdot 001$ \\
\hline Exposure to temperature & $1 \cdot 32(1 \cdot 27)$ & $2 \cdot 41(1 \cdot 14)$ & $0 \cdot 001$ \\
\hline Lifting & $3.41(3.05)$ & $4 \cdot 37(2 \cdot 78)$ & $0 \cdot 001$ \\
\hline Bending & $3 \cdot 45(2 \cdot 43)$ & $3.70(1.93)$ & $0 \cdot 029^{\dagger}$ \\
\hline \multicolumn{4}{|l|}{ Job design } \\
\hline \multicolumn{4}{|l|}{ Work schedules } \\
\hline Take over shift at short notice & $2 \cdot 22(0 \cdot 77)$ & $2 \cdot 02(0 \cdot 72)$ & $0 \cdot 001$ \\
\hline Opportunity to change shift & $4 \cdot 17(1 \cdot 20)$ & $3 \cdot 80(1.05)$ & $0 \cdot 001$ \\
\hline Weekends worked/month (number)* & $2 \cdot 56(0 \cdot 86)$ & $2.60(0.79)$ & $0 \cdot 449$ \\
\hline Consecutive working days* & $6 \cdot 19(2 \cdot 27)$ & $6 \cdot 76(2 \cdot 12)$ & $0 \cdot 001$ \\
\hline Satisfaction with working time (well-being) & $4 \cdot 50(1 \cdot 0)$ & $4 \cdot 17(1 \cdot 17)$ & $0 \cdot 001$ \\
\hline Satisfaction with working time (private life) & $4 \cdot 15(1 \cdot 17)$ & $3.85(1.25)$ & $0 \cdot 001$ \\
\hline Like to change present shift & $2 \cdot 52(1 \cdot 12)$ & $2.65(1.12)$ & $0 \cdot 05$ \\
\hline \multicolumn{4}{|l|}{ Job demands and stressors } \\
\hline Job security & $3.05(0 \cdot 82)$ & $2.97(0.77)$ & $0 \cdot 001$ \\
\hline Workload & $3.08(0.72)$ & $3.34(0.58)$ & $0 \cdot 001$ \\
\hline Emotional demands & $3.34(0.63)$ & $3.67(0.56)$ & $0 \cdot 001$ \\
\hline Uncertainty about treatment & $2 \cdot 44(0 \cdot 61)$ & $2 \cdot 76(0 \cdot 71)$ & $0 \cdot 001$ \\
\hline Role ambiguity & $2 \cdot 18(0 \cdot 79)$ & $2.72(0.92)$ & $0 \cdot 001$ \\
\hline Role conflict & $2 \cdot 01(0 \cdot 80)$ & $2 \cdot 48(0 \cdot 86)$ & $0 \cdot 001$ \\
\hline Job latitude & $3 \cdot 22(0 \cdot 81)$ & $2 \cdot 92(0 \cdot 74)$ & $0 \cdot 007$ \\
\hline Work-family conflict & $2.64(0.95)$ & $3 \cdot 11(0 \cdot 92)$ & $0 \cdot 001$ \\
\hline Effort-reward imbalance ratio* & $0 \cdot 49(0 \cdot 21)$ & $0 \cdot 68(0 \cdot 28)$ & $0 \cdot 001$ \\
\hline Effort* & $12 \cdot 55(4 \cdot 14)$ & $15 \cdot 94(4 \cdot 42)$ & $0 \cdot 001$ \\
\hline Reward* & $48 \cdot 78(5 \cdot 73)$ & $45 \cdot 28(7 \cdot 11)$ & $0 \cdot 001$ \\
\hline \multicolumn{4}{|l|}{ Organisational climate } \\
\hline Meaning of work & $4.37(0 \cdot 62)$ & $4 \cdot 21(0 \cdot 69)$ & $0 \cdot 001$ \\
\hline Relationships with nursing management & $3.08(0.90)$ & $2 \cdot 84(0 \cdot 91)$ & $0 \cdot 001$ \\
\hline Relationships with team & $4 \cdot 19(0 \cdot 85)$ & $4 \cdot 16(0 \cdot 81)$ & $0 \cdot 568$ \\
\hline Relationships with doctors & $3.55(0 \cdot 84)$ & $3.48(0.91)$ & $0 \cdot 165$ \\
\hline Relationships with administration & $3.44(0 \cdot 88)$ & $2.93(0.89)$ & $0 \cdot 001$ \\
\hline Quality of leadership & $3.32(1.09)$ & $3 \cdot 27(1 \cdot 08)$ & $0 \cdot 459$ \\
\hline Social support from superior & $3 \cdot 24(0.96)$ & $3.26(0.93)$ & $0 \cdot 625$ \\
\hline Social support from colleagues & $3.53(0.77)$ & $3.50(0 \cdot 73)$ & $0 \cdot 458$ \\
\hline Days dedicated for professional development/year* & $6 \cdot 43(18 \cdot 6)$ & $6 \cdot 06(21 \cdot 2)$ & $0 \cdot 001^{\dagger}$ \\
\hline Satisfaction with handover shifts & $3.75(1.25)$ & $3 \cdot 25(1 \cdot 15)$ & $0 \cdot 001$ \\
\hline
\end{tabular}




\begin{tabular}{|c|c|c|c|}
\hline & $\begin{array}{l}\text { Attractive hospitals } \\
\text { ( } n=401 \text { nurses) }\end{array}$ & $\begin{array}{l}\text { Conventional hospitals } \\
\text { ( } n=774 \text { nurses) }\end{array}$ & $P$ value \\
\hline \multicolumn{4}{|l|}{ Work adjustments antecedents to turnover } \\
\hline Job satisfaction & $3.46(0.54)$ & $3 \cdot 20(0 \cdot 65)$ & $0 \cdot 001$ \\
\hline Pay satisfaction in relation to needs & $2 \cdot 86(0 \cdot 93)$ & $2.42(0.99)$ & $0 \cdot 001$ \\
\hline Pay satisfaction compared to other institutions & $2 \cdot 94(0 \cdot 85)$ & $2 \cdot 87(0.95)$ & $0 \cdot 292$ \\
\hline Organizational commitment & $3.52(0 \cdot 70)$ & $3.25(0 \cdot 85)$ & $0 \cdot 001$ \\
\hline Burnout & $2 \cdot 16(0 \cdot 78)$ & $2 \cdot 91(0 \cdot 68)$ & $0 \cdot 001$ \\
\hline Work ability* & $40 \cdot 39(5 \cdot 01)$ & $37 \cdot 66(4 \cdot 52)$ & $0 \cdot 001$ \\
\hline Intention to leave & $2.36(0.55)$ & $2.59(0.70)$ & $0 \cdot 001$ \\
\hline
\end{tabular}

The values are given as mean (SD) on 1-5 scale except otherwise specified $\left({ }^{*}\right)$; ${ }^{\dagger}$ Mann-Whitney test.

\section{Physical health-related exposure}

Dramatically lower health hazard exposure was reported in attractive hospitals, although hazard exposure related here to a variety of factors, i.e. environmental or architectural factors such as noise (mean $=1.25$ vs. $2.66 ; P<0.001$ ) and temperature (mean $=1.32$ vs. $2.41 ; P<0.001)$; hospitalspecific risks as exposure to toxic substances (mean $=1 \cdot 3$ vs. $0.22 ; P<0.001$ ) or exposure to infection (mean $=2.51$ vs. 3.24; $P<0.001)$; and nursing specific characteristic lifting $(m=3.41$ vs. $m=4.37 ; P<0.001)$ and bending $(m=3.45$ vs. $m=3 \cdot 70 ; P=0.029$ ) tasks.

\section{Work schedules}

Nurses in attractive hospitals reported more often that they had to work unscheduled shifts at short notice $(m=2.22$ vs. $m=2.02 ; P<0.001)$. However, they also reported a greater opportunity to change shifts if needed (mean $=4 \cdot 17$ vs. $3 \cdot 80$; $P<0.001$ ), a finding compatible with the fact that nurses are more satisfied when they have control over their working schedules (Krausz et al. 2000). The average number of weekends worked per month was not statistically significantly different, but the maximum number of consecutive working days was lower, by half a day, in attractive hospitals (mean $=6.19$ vs. $6.76 ; P<0.001$ ). In parallel, satisfaction with working time was statistically significantly higher in attractive hospitals (mean $=4.50$ vs. 4.17 for personal wellbeing; $P<0.001$; mean $=4.15$ vs. 3.85 for private life; $P<0.001)$, and nurses did not differ as regards their wishes to change their present shift.

\section{Job demands and stressors}

Job security was higher in attractive hospitals ( $m=3.05$ vs. $m=2.97 ; \quad P<0.001$ ), despite the lower proportion of permanent contracts.
Nurses reported less strain in attractive hospitals than in conventional hospitals. Job demands and stressors were systematically lower in attractive hospitals compared with conventional hospitals. Direct stressors such as workload $($ mean $=3.08$ vs. $3.34 ; P<0.001)$, effort $($ mean $=12.55$ vs. 15.94; $P<0.001$ ) and emotional demands (mean $=3.34$ vs. $3.67 ; P<0.001)$ were more favourable in attractive hospitals. In Belgian institutions, there is no objective workload measure. Nevertheless, nurses felt their workload to be more acceptable in attractive institutions due to a good division of work between staff and a good balance in activities on the different shifts.

Uncertainty about treatments, a dimension of Nursing Stress Scale (Gray-Toft \& Anderson 1985) designed to assess the degree to which nurses receive inadequate information about the medical condition of a patient (e.g. because of the absence of physicians), was also statistically significantly lower in attractive hospitals (mean $=2.44$ vs. $2 \cdot 76$; $P<0.001)$. In the same vein, role ambiguity - the available information required to perform tasks and get appropriate feedback on performance - and role conflicts - the occurrence of contradictory requests - were lower in attractive hospitals (respectively mean $=2.18$ vs. $2.72 ; P<0.001$ and mean $2 \cdot 01$ vs. $2 \cdot 48 ; P<0.001)$.

Balancing factors, such as job latitude (mean $=3.22$ vs. $2.92 ; \quad P<0.01$ ) and rewards $($ mean $=4.43$ vs. 4.12 ; $P<0.001)$ were more favourable in attractive hospitals. Moreover, nurses in attractive institutions reported fewer work-family conflicts ( $m=2.64$ vs. $m=3.11 ; P<0.001$ ), resulting from good balance between work demands at hospital (workload, work schedules and home-workplace distance) and personal life.

\section{Organizational climate}

Dimensions of organizational climate were generally rated 'good' in attractive and conventional hospitals. Meaning of 
work was statistically significantly higher in attractive institutions (mean $=4.37$ vs. $4.21 ; P<0.001$ ). Relationships with team and physicians, social support from superior and colleagues, and quality of nursing leadership were similar in both groups. Relationships with nursing management (mean $=3.08$ vs. $2.84 ; P<0.001$ ) as well as relationships with general management $($ mean $=3.44$ vs. $2.93 ; P<0.001$ ) indicated that communication was better and that the hierarchical structure was flatter in attractive hospitals. Satisfaction with handover shifts was another indicator of a better communication between nurses in attractive hospitals (mean $=3.75$ vs. $3.25 ; P<0.001)$.

\section{Work adjustment prior to turnover}

Job attitudes were systematically more favourable in attractive institutions. In attractive hospitals, nurses reported higher job satisfaction (mean $=3.46$ vs. $3.20 ; P<0.001$ ), higher affective commitment to the institution (mean $=3.52$ vs. $3.25 ; \quad P<0.001)$ and a lower intention to leave the institution (mean $=2.36$ vs. $2.59 ; P<0.001$ ). Intention to leave the institution was clearly a valid predictor of turnover behaviour in the present study, since hospitals were classified according to their turnover rate. Satisfaction with salary was either higher in attractive hospitals (satisfaction with pay in relation to needs), or equivalent (satisfaction with pay comparing to other hospitals).

Nurses reported a lower burnout level in attractive hospitals $($ mean $=2 \cdot 16$ vs. $2.91 ; P<0.001)$, indicating better mental well-being. Work ability index, a self-assessed measure that refers to both individual and occupational factors that are essential to a person's ability to cope in working life (Ilmarinen et al. 1997), was rated 'good' in both groups of hospitals, but was higher in attractive hospitals (mean $=40.39$ vs. $37.66 ; P<0.001$ ), although nurses in the attractive hospitals were slightly older (mean $=38.85$ vs. $37 \cdot 24$ years; $P<0.01$ ).

\section{Discussion}

In this study, which was designed to contrast the characteristics of low and high turnover hospitals, structural features were equally distributed between the two subsets, whereas most differences concerned nurses' perceptions.

As stated above, the highly regulated hospital system in Belgium may explain the absence of structural differences between attractive and conventional hospitals.

Nurses' demographics and employment differed between attractive and conventional hospitals. Higher age, number of children, tenure and lower opportunity for job alternatives in the same area indicated more stability, stronger bonds between nurses and attractive hospitals and, possibly, higher perceived costs for nurses leaving an attractive hospital. Tenure for example can be considered as the result of attachment as well as a source of possible advantages, such as job stability and advancement, which could be forfeited if a nurse leaves his/her hospital (Mitchell et al. 2001a, 2001b, Holtom \& O’Neill 2004). Shorter home-workplace travelling distances for nurses working in attractive institutions could be another factor linking them to their workplace. The higher proportion of employees with permanent contracts was surprising in high-turnover hospitals and might reflect ineffective strategies for nurse attraction and retention.

The most striking differences concerned nurses' perceptions towards three components of their work environment: exposure to physical health-related factors, work schedules and job demands and stressors.

Dramatically lower health hazard exposure was reported in attractive hospitals. Whether this indicated a true differential exposure or better occupational safety could not be explored. However, two arguments favour the latter interpretation: (1) according to the organizational assessment, the nature of occupational hazards did not differ between attractive and conventional hospitals; and (2) systematically reduced hazard exposure in attractive hospitals, which implies that similar risks were better managed.

As regards working schedules, these were slightly better in attractive hospitals but nurses' attitudes were much more positive.

Job demands and stressors were lower in attractive hospitals, compared with conventional hospitals, and balancing factors, such as job latitude and rewards, were more favourable in attractive hospitals. Job latitude refers to the amount of discretion that workers exercise over when and how they perform their work. This dimension is of considerable importance since, in a context of increasing job demands, increase in job control helps nurses in coping and maintaining high job satisfaction (Fox et al. 1993).

Among job stressors, job security was not very different, although statistically significant, between attractive and conventional hospitals, probably because a vast majority of nurses had permanent contracts. This result can be examined together with work-family conflicts, continuing education and learning opportunities, work ability and satisfaction with pay, to form a composite construct that could be named 'job future'. Lower work-family conflicts in attractive hospitals suggest more harmony between professional and private life and better opportunities to fulfil kinship responsibilities, an important element to consider in a mostly female population. Days dedicated to professional development, a measure of 
learning opportunities, was higher in attractive hospitals. Perceived health and employability, measured by the WAI, and satisfaction with salary were better in attractive hospitals. Thus, nurses in attractive hospitals could be deemed to have more conditions for sustainable professional activity in their present employment.

As regards dimensions of organizational climate, relationships with team and physicians, social support from superior and colleagues, and quality of nursing leadership, were similar in both groups, with a small non-statistically significant but systematically better levels in attractive hospitals. However, quality of communication was statistically significantly better in attractive hospitals. Better communication with team, nursing management and physicians might explain why role ambiguity and role conflicts were lower in attractive hospitals. In healthcare settings, adequate and timely interpersonal communication is also considered a determinant of team effectiveness and quality health care, which in turn has been shown to influence job satisfaction (Knaus et al. 1986, Vandenberghe \& D'hoore 1999).

Attractive hospitals better managed balances between demands and rewards, in the broad sense, which resulted in better psychological work adjustments. Psychological adjustments can be interpreted in the light of the theory of social exchange, which claims that people expect reciprocity from their investments (workload), and explains why a lack of reciprocity (reward and control) triggers burnout and job dissatisfaction. According to Eisenberger et al. (2002), employees form general beliefs about how much the organization values their contributions and cares about their wellbeing and, based on the norm of reciprocity, employees reciprocate such support with emotional commitment to the organization, work effort in standard job activities, and extra-role performance such as innovative problem-solving. Effort-reward imbalance is an explicit measurement of this equilibrium, which has non-trivial consequences for mental and physical health (van Vegchel et al. 2005). Indeed, lower 'efforts' (job demands and stressor levels) and adequate 'rewards' (social support, respect from colleagues, job control and salary) have been shown to result in lower burnout, higher job satisfaction and commitment in nurses (Bakker et al. 2000), which in turn reduce intention to leave and ultimately influence turnover behaviour.

Job satisfaction, commitment and meaning of work, which were higher in attractive hospitals, are complex constructs with multiple antecedents. They may be considered as a result of the combination of job demand/control balance, symbolic and tangible rewards, reduced work-family conflicts, influence at work, proficient nurse leadership, and good communication between colleagues and between nurses and physicians. They also result from trust, respect, recognition of employee role and congruence between personal and organizational values, i.e. organizational culture and practices, which are more distant antecedents of job design and psychological work adjustments. The importance of organizational culture for healthcare processes and health outcomes has been demonstrated in the famous Bristol case (http://www.bristol-inquiry.org.uk/), where a lack of clinical leadership, of openness and teamwork, and the absence of a culture of safety and quality, among others, were incriminated in the excess mortality of a paediatric cardiac surgery unit. In more positive examples, the influence of organizational culture has been shown or invoked as ground for successful implementation of quality improvement programmes (Berlowitz et al. 2003) and healthcare reforms (Franco et al. 2002), as prerequisite for effective risk management (Reason 2000), and as sources of nurse job satisfaction (Verplanken 2004). Congruence, or fit, between organizational and employee values as well as employee plans and prospects has been shown to be predictive of retention, while misfit is a predictor of turnover (Vandenberghe 1999). Fit can be defined as an employee's perceived compatibility or comfort with an organization and with its environment (Mitchell et al. 2001a). Our results were compatible with the theory: nurses in attractive hospitals reported higher satisfaction with the value of their work, in terms of better fit between work content and their professional nursing ideal, better fit between their personal and professional values and the philosophy of care advocated by the nursing sector, and patient centredness, visible through a charter accepted and shared by professionals.

\section{Modelling the attractive hospital}

The distinct configurations of attractive and conventional hospitals are hard to explain without reference to some intentionality underlying covariation between variables and leading to so many measured differences. Overall, attractive hospitals possessed the many features of healthy workplaces, defined as 'organizations characterized by intentional, systematic and collaborative efforts to maximize employee wellbeing and productivity by providing well-designed and meaningful jobs, a supportive social-organizational environment, and accessible and equitable opportunities for career and work-life enhancement' (Wilson et al. 2004, p. 567). There are few published reports of tested conceptualizations of healthy work organizations, but virtually all the links presented above between organizational culture, organizational climate, health and well-being, job demands/control and attitudinal outcomes find empirical support. 


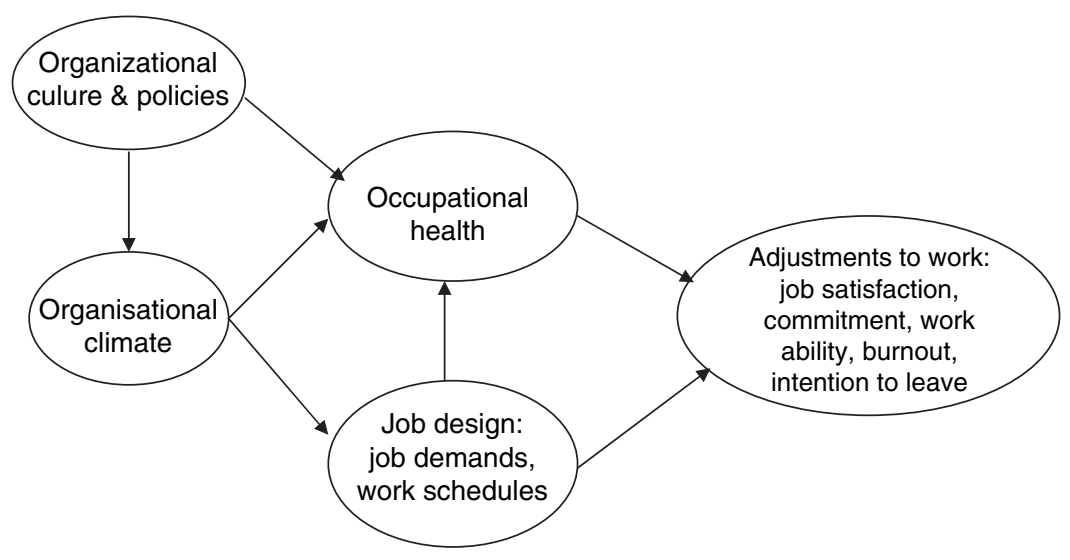

Figure 1 Model of attractive hospitals, showing hypothetical associations between variables.

In line with research by Danna and Griffin (1999), Lowe et al. (2003), Ellenbecker (2004) and Wilson et al. (2004), an integrative model which attempts to provide a systematic accounting of job-nurse interactions and macro-organizational influences in attractive hospitals was developed (Figure 1). The model starts with organizational culture and policies, which are considered here to be under the control of the management: management creates and changes culture, develops policies and improves practices through teamwork and education. We hypothesize that additional features were present in attractive hospitals. Firstly, management in a healthy workplace implies a culture of openness and respect, likely prerequisites for better organizational climate and reduced hazard exposure. Such a culture is translated into fairness and justice in human resources management practices, resulting in feelings of meaningful and valued work. These elements are characteristics of a high degree of organizational support (caring organization), associated with feelings of recognition and reward. In parallel, we hypothesize that open and timely communication was allied to some degree of formalization, which decreases role ambiguity and role conflicts, and increases job autonomy, with resulting lower risk of burnout. Secondly, we assume that attractive hospitals were rich in social capital, defined as 'features of social organization such as trust, norms and networks that can improve the efficiency of society by facilitating coordinated action'. Such organizations benefit from high levels of trust between workers and are less hierarchical (Rafferty et al. 2001). Thirdly, congruence between the missions of healthcare settings and their practices implies that attractive organizations provided the resources to achieve high quality care. When these organizational attributes were combined, their consequences were clear: nurses in attractive institutions reported a higher job satisfaction, a higher affective commitment to the institution and a lower intent to leave the institution.

\section{Strengths and weaknesses of qualitative comparative analysis}

Caution is required when interpreting the organizational configuration of Belgian attractive hospitals because of several study limitations. Firstly, we forced the contrast between two small subsets of hospitals on the basis of turnover quartiles. In the real world, such a dichotomy would not be expected. However, when the sample of hospitals was split into three or two groups, according to terciles or the median, respectively, distinctive profiles were still present although less impressive. Individual hospital profiles showed that conventional hospitals sometimes performed as well as attractive hospitals. The most constant differences were risk exposure, emotional demands, role ambiguity and conflicts, work-family conflicts, effortreward imbalance and meaning of work. Secondly, we do not know how attractive hospitals performed on other dimensions, such as quality of care and patient satisfaction. Some studies indicate, however, that patients are more satisfied in hospitals where nurses are less exhausted and feel their work more meaningful (Leiter et al. 1998). Thirdly, the nursing human resource market in Belgium was and is still currently favourable to nurses' mobility. The demand for skilled nurses makes it easy for them to leave one healthcare setting for another without leaving the nursing profession. A change in the nursing market towards nurse surplus would probably reduce the impact of hospital attractiveness on nurse turnover behaviours.

The convenience sample and the fairly low response rate of $54 \%$ should also be mentioned as weaknesses. Nevertheless, this response rate compares favourably with that usually reported in studies nursing (e.g. $27 \%$ in Omdahl \& O'Donnell 1999). It should also be noted that in Belgium studies conducted with nurses often suffer from low response rates (Stordeur et al. 2000, 2001). This is due to nurses being frequently surveyed for research purposes, which generates work overload and reluctance to participate. Moreover, many 


\section{What is already known about this topic}

- Turnover is one possible origin of nurse staffing problems and can be either voluntary or involuntary.

- Extensive literature reviews on turnover emphasize the role of managerial practices and organizational factors in turnover, highlighting the concept of a common predisposing climate for turnover.

- In countries facing severe shortages and a high nurse mobility, some healthcare settings succeed in recruitment and retention of nurses, leading to the concept of Magnet Hospitals.

\section{What this paper adds}

- Attractive hospitals have many of the features of healthy workplaces, are less hierarchical and benefit from high levels of trust between workers.

- Attractive hospitals have a distinctive profile characterized by intentional, systematic and collaborative efforts to maximize employee well-being by providing well-designed and meaningful jobs, a supportive socialorganizational environment, and accessible and equitable opportunities for professional development and work-life enhancement.

- Attractive hospitals adequately manage the balance between demands and rewards, which results in better psychological work adjustment.

statistical tests were performed and thus the possibility of type I errors exists.

The strength of this study lies in analysing a comprehensive set of multiple interconnected or nested factors. Identifying organizational and managerial practices common to attractive hospitals is a first step to help organizations effectively manage turnover. Elaborating retention strategies is another issue. Organizational features are key factors for nurse retention, but other models might enrich the span of solutions to the problem. Some of our findings, such as shorter homeworkplace travelling distances, work-family balance and the fit between personal and organizational values, support the theory of job embeddedness (Mitchell et al. 2001a, 2001b, Holtom \& O’Neill 2004, Lee et al. 2004). According to Mitchell and colleagues, staying in and leaving an organization are distinct processes. Managers should be aware that strategies for nurse retention are not limited to increasing nurse satisfaction. Further research is needed to explore the effectiveness of retention strategies based on 'attitudinal theory' of turnover, complemented by the 'job embeddedness' theory of retention.

\section{Conclusion}

Throughout the world, nursing and other researchers look for the means to alleviate national nursing shortages or, more humbly, to encourage nurse retention in health care. Research and professional initiatives have increased the visibility of attractive institutions in the United States of America (USA), Canada, New Zealand, Germany, the United Kingdom (UK) and Belgium. Our results suggest that hospitals could work on their attractiveness through the improvement of workplace well-being. The promotion of the concept of attractive institutions, termed Magnet Hospitals in the USA, could serve as a catalyst for widespread improvement in nurses' work environments in European healthcare settings.

\section{Funding}

This research was supported by a grant from the European Union (fifth framework programme, QLK6-CT-200100475). Title of the project and acronym: Nurses Early Exit Study (NEXT-Study).

\section{Author contributions}

SS, WD and NEXT Group were responsible for the study conception and design and SS and WD were responsible for the drafting of the manuscript. SS performed the data collection SS and WD performed the data analysis. WD and NEXT Group obtained funding and SS provided administrative support. WD provided statistical expertise. SS and WD made critical revisions to the paper. WD supervised the study.

\section{References}

Aiken L.H. (2002) Superior outcomes for magnet hospitals: the evidence base. In Magnet Hospitals Revisited: Attraction and Retention of Professional Nurses (McClure M.L. \& Hinshaw A.S., eds), pp. 61-81. American Nurses Association, Washington, DC.

Aiken L.H., Clarke S.P., Sloane D.M., Sochalski J.A., Buse R., Clarke H., Giovannetti P., Hunt J., Rafferty A.M. \& Shamian J. (2001) Nurses' reports on hospital care in five countries. Health Affairs 20, 43-53.

Allen N.J. \& Meyer J.P. (1990) The measurement and antecedents of affective continuance and normative commitment to the organization. Journal of Occupational Psychology 63, 1-18.

Bakker A.B., Killmer C.H., Siegriest J. \& Schaufeli W.B. (2000) Effort-reward imbalance and burnout among nurses. Journal of Advanced Nursing 31, 884-891.

Berlowitz D.R., Young G.J., Hickey E.C., Saliba D., Mittman B.S., Czarnowski E., Simon B., Anderson J.J., Ash A.S., Rubenstein L.V. \& Moskowitz M.A. (2003) Quality improvement implementation in the nursing home. Health Services Research 38, 65-83. 
Bloom J.R., Alexander J.A. \& Nuchols B.A. (1992) The effect of the social organization of work on the voluntary turnover rate of hospital nurses in the United States. Social Science and Medicine 34, 1413-1424.

Borritz M. \& Kristensen T.S. (2001) Copenhagen Burnout Inventory: Normative data from a representative Danish population on Personal burnout and Results from the PUMA study on Personal Burnout, Work Burnout, and Client Burnout. National Institute of Occupational Health, Copenhagen.

Buchan J. (1994) Nursing shortages and human resource planning. International Journal of Nursing Studies 31, 460-470.

Campion M.A., Papper E.M. \& Medsker G.J. (1996) Relations between work team characteristics and effectiveness: a replication and extension. Personnel Psychology 49, 429-452.

Danna K. \& Griffin R.W. (1999) Health and well-being in the workplace: a review and synthesis of the literature. Journal of Management 25, 357-384.

De Jonge J., Mulder M.J.G.P. \& Nijhuis F.J.N. (1999) The incorporation of different demand concepts in the Job DemandControl Model: Effects on health care professionals. Social Science and Medicine 48, 1149-1160.

Delery J.E. \& Doty D.H. (1996) Modes of theorizing in strategic human resource management: tests of universalistic, contingency, and configurational performance predictions. Academy of Management Journal 39, 802-835.

Eisenberger R., Stinglhamber F., Vandenberghe C., Sucharski I.L. \& Rhoades L. (2002) Perceived supervisor support: contributions to perceived organizational support and employee retention. Journal of Applied Psychology 87, 565-573.

Ellenbecker C.H. (2004) A theoretical model of job retention for home health care nurses. Journal of Advanced Nursing 47, 303-310.

Finlayson B., Dixon J., Meadows S. \& Blair G. (2002) Mind the gap: the extent of the NHS nursing shortage. British Medical Journal $325,538-541$.

Fiss P.C. (2005) A set-theoretic approach to organizational configurations. Academy of Management Review Retrieved from http:// www.compasss.org/fiss2005.pdf on 31 May 2006.

Fox M.L., Dwyer D.J. \& Ganter D.C. (1993) Effects of stressful job demands and control on physiological and attitudinal outcomes in a hospital setting. Academy of Management Journal 36, 289-318.

Franco L.M., Bennett S. \& Kanfer R. (2002) Health sector reform and public sector health worker motivation: a conceptual framework. Social Science and Medicine 54, 1255-1266.

Gaertner S. (1999) Structural determinants of job satisfaction and organizational commitment in turnover models. Human Resource Management Review 9, 479-493.

Gray-Toft P. \& Anderson J.G. (1985) Organizational stress in the hospital: development of a model for diagnosis and prediction. Health Services Research 19, 753-774.

Halbur B.T. (1983) Nursing personnel in nursing homes: a structural approach to turnover. Work and Occupations 10, 381-411.

Hasselhorn H.M., Tackenberg P. \& Mueller B. (eds) (2003) Working conditions and intent to leave the profession among nursing staff in Europe. Working Life Research report 7:2003, ISSN 1404-790X, pp. 258, National Institute for Working Life, Stockholm.

Hayes L.J., O’Brien-Pallas L., Duffield C., Shamian J., Buchan J., Hughes F., Spence Lashinger H.K., North N. \& Stone P.W. (2006)
Nurse turnover: a literature review. International Journal of Nursing Studies 43, 237-263.

Holtom B.C. \& O’Neill B.S. (2004) Job embeddedness: a theoretical foundation for developing a comprehensive nurse retention plan. Journal of Nursing Administration 34, 216-227.

Ilmarinen J., Tuomi K. \& Klockars M. (1997) Changes in the work ability of active employees over a 11-year period. Scandinavian Journal of Work, Environment and Health 23, 49-57.

Irvine D.M. \& Evans M.G. (1995) Job satisfaction and turnover among nurses: integrating research findings across studies. Nursing Research 44, 246-253.

Knaus W.A., Draper E.A., Wagner D.P. \& Zimmerman J.E. (1986) An evaluation of outcome from intensive care in major medical centers. Annals of Internal Medicine 104, 410-418.

Kramer M. (1990) The magnet hospitals: excellence revisited. Journal of Nursing Administration 20, 35-44.

Kramer M. \& Schmalenberg C. (1988) Magnet Hospitals: institutions of excellence. Journal of Nursing Administration 18, 13-24.

Krausz M., Sagie A. \& Bidermann Y. (2000) Actual and preferred work schedules and scheduling control as determinants of job related attitudes. Journal of Vocational Behavior 56, 1-11.

Kristensen T.S. (2000) A New Tool for Assessing Psychosocial Factors at Work: the Copenhagen Psychological Questionnaire. National Institute of Health, Copenhagen.

Lee T.W., Mitchell T.R., Sablynski C.J., Burton J.P. \& Holtom B.C. (2004) The effects of job embeddedness on organizational citizenship, job performance, volitional absences, and voluntary turnover. Academy of Management Journal 47, 711-722.

Leiter M.P., Harvie P. \& Frizzell C. (1998) The correspondence of patient satisfaction and nurse burnout. Social Sciences and Medicine 47, 1611-1617.

Leveck M.L. \& Jones C.B. (1996) The nursing practice environment, staff retention, and quality of care. Research in Nursing and Health 19, 331-343.

Lowe G.S., Schellenberg G. \& Shannon H.S. (2003) Correlates of employees' perceptions of a healthy work environment. American Journal of Health Promotion 17, 390-399.

McClure M.L. \& Hinshaw A.S. (2002) Magnet Hospitals revisited: Attraction and Retention of Professional Nurses. American Nurses Association, Washington, DC.

McClure M.L., Poulin M., Sovie M. \& Wandelt M. (1983) Magnet Hospitals: Attraction and Retention of Professional Nurses. American Nurses Association, Kansas City, MO.

Meyer J.P. \& Allen N.J. (1997) Commitment in the workplace: Theory, Research, and Application. Sage Publications, Thousand Oaks, CA.

Meyer J.P. \& Herscovitch L. (2001) Commitment in the workplace. Toward a general model. Human Resource Management Review 11, 299-326.

Mitchell T.R., Holtom B.C., Lee T.W. \& Erez M. (2001a) Why people stay: using job embeddedness to predict voluntary turnover. Academy of Management Journal 44, 1102-1121.

Mitchell T.R., Holtom B.C. \& Lee T.W. (2001b) How to keep your best employees: the development of an effective attachment policy. Academy of Management Excellence 15, 96-108.

Netemeyer R.G., Boles J.S \& McMurrian R. (1996) Development and validation of work-family conflict and family-work conflict scales. Journal of Applied Psychology 81, 400-410. 
Omdahl B.L. \& O’Donnell C. (1999) Emotional contagion, empathic concern and communicative responsiveness as variables affecting nurses' stress and occupational commitment. Journal of Advanced Nursing 29, 1351-1359.

Price J.L. (1977) The Study of Turnover. Iowa State University Press, Ames, IA.

Price J.L. \& Mueller C.W. (1981) Professional Turnover: The Case for Nurses. Iowa State University Press, Ames, IA.

Rafferty A.M., Ball J. \& Aiken L.H. (2001) Are teamwork and professional autonomy compatible, and do they result in improved hospital care?. Quality in Health Care 10(Suppl. II), ii32-ii37.

Ragin C.C. (1999) Using qualitative comparative analysis to study causal complexity. Health Services Research 34, 1225-1239.

Reason J. (2000) Human error: models and management. British Medical Journal 320, 768-770.

Shader K., Broome M., Broome C.D., West M.E. \& Nash M. (2001) Factors influencing satisfaction and anticipated turnover for nurses in an Academic Medical Centre. Journal of Nursing Administration 31, 210-216.

Siegrist J. (1996) Adverse health effects of high effort - low reward conditions at work. Journal of Occupational Health Psychology 1, $27-43$.

Simoens S., Villeneuve M. \& Hurst J. (2005) Tackling Nurse Shortages in OECD Countries. OECD Health Working Papers 19, DELSA/ELSA/WD/HEA (2005)1.

Sjögren K., Fochsen G., Josephson M. \& Lagerström M. (2004) Reasons for leaving nursing care and improvements needed for considering a return: a study among Swedish nursing personnel. International Journal of Nursing Studies 42, 751-758.

Spencer D.G. (1986) Employee voice and employee retention. Academy of Management Journal 29, 488-502.

Stordeur S., Vandenberghe C. \& D'hoore W. (2000) Leadership styles across hierarchical levels in nursing departments. Nursing Research 49, 37-43.

Stordeur S., Vandenberghe C. \& D'hoore W. (2001) Leadership, organizational stress, and emotional exhaustion among hospital nursing staff. Journal of Advanced Nursing 35, 1-10.

Strachota E., Normandin P., O'Brien N., Clary M. \& Krukow B. (2003) Reasons registered nurses leave or change employment status. Journal of Nursing Administration 33, 111-117.
Tai T.W.C., Bame S.I. \& Robinson C.D. (1998) Review of nursing turnover research, 1977-1996. Social Science and Medicine 47, 1905-1924.

The HSM Group, Ltd (2002) Acute care hospital survey of RN vacancy and turnover rates in 2000. Journal of Nursing Administration 32, 437-439.

Theorell T., Perski A., Akersted T., Sigala F., Ahlerg-Hulten G., Svensson J. \& Eneroth P. (1988) Changes in job strain in relation to changes in physiological state. A longitudinal study. Scandinavian Journal of Work, Environment \& Health 13, 189196.

Tuomi K., Ilmarinen J., Eskelinen L., Jarvinen E., Toikkanen J. \& Klockars M. (1991) Prevalence and incidence rates of diseases and work ability in different work categories of municipal occupations. Scandinavian Journal of Work, Environment \& Health 17, 67-74.

Vandenberghe C. (1999) Organizational culture, person-culture fit, and turnover: a replication in the health care industry. Journal of Organizational Behavior 20, 175-184.

Vandenberghe C. \& D'hoore W. (1999) Validity evidence for the nurse-physician intensive care units questionnaire in a Belgian context. European Review of Applied Psychology 49, 67-75.

Van der Heijden B.I.J.M. (1998) The Measurement and Development of Professional Expertise Throughout the Career. Dissertation, University of Twente, Enschede.

van Vegchel N., de Jonge J., Bosma H. \& Schaufeli W. (2005) Reviewing the effort-reward imbalance model: drawing up the balance of 45 empirical studies. Social Science and Medicine 60, 1117-1131.

Verplanken B. (2004) Value congruence and job satisfaction among nurses: a human relations perspective. International Journal of Nursing Studies 41, 599-605.

Wilson M.G., Dejoy D.M., Vandenberg R.J., Richardson H.A. \& McGrath A.L. (2004) Work characteristics and employee health and well-being: test of a model of healthy work organization. Journal of Occupational and Organizational Psychology 77, 565-588.

Zurn P., Dolea C. \& Stilwell B. (2005) Nurse Retention and Recruitment: Developing a Motivated Workforce. World Health Organization - Department of Human Resources for Health, ICN 2005 Issue 4, Geneva, Switzerland.

\section{Appendix}

\begin{tabular}{|c|c|c|c|c|}
\hline & Source & $\begin{array}{l}\text { Number } \\
\text { of items }\end{array}$ & Range & Alpha \\
\hline \multicolumn{5}{|l|}{ Physical health-related factors } \\
\hline Exposure to toxic substances & NEXT & 1 & 1-not exposed to 5-very hazardous & \\
\hline Exposure to infection & NEXT & 1 & 1-not exposed to 5 -very hazardous & \\
\hline Exposure to noise & NEXT & 1 & 1-not exposed to 5-very hazardous & \\
\hline Exposure to temperature & NEXT & 1 & 1-not exposed to 5-very hazardous & \\
\hline Lifting and bending & NEXT & 8 & 0 times a day to 10 times a day & 0.86 \\
\hline \multicolumn{5}{|l|}{ Job design } \\
\hline \multicolumn{5}{|l|}{ Job demands and stressors } \\
\hline Quantitative demands & $\begin{array}{l}\text { COPSOQ } \\
(\text { Kristensen 2000) }\end{array}$ & 5 & 1-never to 5 -always & 0.78 \\
\hline Emotional demands & De Jonge et al. 1999 & 4 & 1-never to 5-always & 0.70 \\
\hline
\end{tabular}


Appendix (Continued)

\begin{tabular}{|c|c|c|c|c|}
\hline & Source & $\begin{array}{l}\text { Number } \\
\text { of items }\end{array}$ & Range & Alpha \\
\hline Uncertainty about treatment & $\begin{array}{l}\text { NSS (Gray-Toft \& } \\
\text { Anderson 1985) }\end{array}$ & 5 & 1 -never to 5 -very often & 0.74 \\
\hline Role ambiguity & NEXT & 1 & 1-never to 5-always & \\
\hline Role conflict & NEXT & 1 & 1-never to 5-always & \\
\hline Job insecurity & $\begin{array}{l}\text { COPSOQ } \\
\text { (Kristensen 2000) }\end{array}$ & 2 & 1 -no to 2 -yes & \\
\hline Job latitude & $\begin{array}{l}\text { Demand-Control Quest. } \\
\text { (Theorell et al. 1988) }\end{array}$ & 4 & $\begin{array}{l}\text { 1-totally inaccurate to } 5 \text {-totally } \\
\text { accurate }\end{array}$ & 0.80 \\
\hline Work-family conflict & Netemeyer et al. (1996) & 5 & 1-totally disagree to 5 -totally agree & 0.86 \\
\hline Effort & ERI (Siegrist 1996) & 6 & 1-no distress to 5 -very much distress & 0.71 \\
\hline Reward & ERI (Siegrist 1996) & 11 & 1-no distress to 5 -very much distress & 0.72 \\
\hline \multicolumn{5}{|l|}{ Work schedules } \\
\hline Having to work at short notice & NEXT & 1 & $\begin{array}{l}\text { 1-never to } 4 \text {-more than five times } \\
\text { per month }\end{array}$ & \\
\hline Number of weekends worked/month & NEXT & 1 & 1-no WE to 5 -more or less 4 & \\
\hline Consecutive working days & NEXT & 1 & number of days & \\
\hline Influence on planning rota & NEXT & 1 & 1-no influence to 5 -I decide myself & \\
\hline Satisfaction with working time (well-being) & NEXT & 1 & 1-no to 2 -yes & \\
\hline Satisfaction with working time (private life) & NEXT & 1 & 1 -no to 2 -yes & \\
\hline Like to change present shift & NEXT & 1 & 1-no to 3-yes, definitely & \\
\hline \multicolumn{5}{|l|}{ Organizational climate } \\
\hline Meaning of work & $\begin{array}{l}\text { COPSOQ } \\
\text { (Kristensen 2000) }\end{array}$ & 3 & $\begin{array}{l}\text { 1-to a small extent to } 5 \text {-to a large } \\
\text { extent }\end{array}$ & 0.82 \\
\hline Relationships with nursing managers & NEXT & 1 & $\begin{array}{l}\text { 1-hostile and tense to } 5 \text {-friendly } \\
\text { and relaxed }\end{array}$ & \\
\hline Relationships with team & NEXT & 1 & $\begin{array}{l}\text { 1-hostile and tense to 5-friendly } \\
\text { and relaxed }\end{array}$ & \\
\hline Relationships with doctors & NEXT & 1 & $\begin{array}{l}\text { 1-hostile and tense to } 5 \text {-friendly } \\
\text { and relaxed }\end{array}$ & \\
\hline Quality of leadership & $\begin{array}{l}\text { COPSOQ } \\
\text { (Kristensen 2000) }\end{array}$ & 4 & 1-poor quality to 5 -high quality & 0.90 \\
\hline Social support from superior & Van der Heijden (1998) & 4 & 1 -never to 5 -often & 0.81 \\
\hline Social support from colleagues & Van der Heijden (1998) & 4 & 1-never to 5 -often & 0.73 \\
\hline Days dedicated to professional development & NEXT & 1 & Number of days & \\
\hline Satisfaction with handover shifts & NEXT & 1 & 1 -yes to 2 -no & \\
\hline \multicolumn{5}{|l|}{ Work adjustments antecedents to turnover } \\
\hline Job satisfaction & $\begin{array}{l}\text { COPSOQ } \\
\text { (Kristensen 2000) }\end{array}$ & 6 & $\begin{array}{l}\text { 1-very dissatisfied to 4-very } \\
\text { satisfied }\end{array}$ & 0.79 \\
\hline Pay satisfaction in relation to needs & NEXT & 1 & $\begin{array}{l}\text { 1-not at all satisfied to } 5 \text {-very } \\
\text { satisfied }\end{array}$ & \\
\hline Pay satisfaction compared to other institutions & NEXT & 1 & $\begin{array}{l}\text { 1-not at all satisfied to } 5 \text {-very } \\
\text { satisfied }\end{array}$ & \\
\hline Organizational commitment & Allen and Meyer (1990) & 3 & $\begin{array}{l}\text { 1-no, totally inaccurate to } 5 \text {-yes, } \\
\text { totally accurate }\end{array}$ & 0.83 \\
\hline Burnout & $\begin{array}{l}\text { Borritz and } \\
\text { Kristensen (2001) }\end{array}$ & 6 & $\begin{array}{l}\text { 1-almost never to } 5 \text {-almost } \\
\text { every day }\end{array}$ & 0.89 \\
\hline Work ability & WAI (Tuomi et al. 1991) & 26 & Scores from 7 to $49^{\dagger}$ & $*$ \\
\hline Intention to leave & NEXT & 1 & 1-never to 5 -every day & \\
\hline
\end{tabular}

NEXT, Nurses Early Exit Study; COPSOQ, Copenhagen Psychosocial Questionnaire; NSS, Nursing Stress Scale; ERI, Effort-Reward Imbalance; WAI, Work Ability Index.

*Seven dimensions (due to the construction of the WAI, internal consistency cannot be measured).

†Work ability is 'poor' if WAI ranges from 7 to 27, 'moderate' between 28 and 36, 'good' between 37 and 43 , and 'excellent' between 44 and 49. 